\title{
Editorial
}

\section{Engaged Mathematics Learning as/for a Transformative Praxis}

\author{
Basanta Raj Lamichhane ${ }^{1}$ and Niroj Dahal ${ }^{2}$ \\ ${ }^{1}$ Saptagandaki Multiple Campus, Bharatpur, Chitwan, Nepal \\ ${ }^{2}$ Kathmandu University School of Education, Department of STEAM Education, \\ Hattiban, Lalitpur, Nepal \\ Corresponding Editor: mebasanta98@gmail.com
}

\begin{abstract}
Engaged learning in mathematics is essential to students' success and has a significant role in creating a transformative path in mathematics education. Considering this, this editorial attempts to highlight the role of behavioural, cognitive, affective and agentic aspects of engaged learning. It is impossible to bring all aspects of this complex and multidimensional construct in this short editorial; however, we try to open a new avenue by bringing the issue of engaged learning into pedagogical practices of mathematics in the context of Nepal. The discourse opens up how disengaged learning creates a mathematical Othering and its detrimental effects on mathematics education. Moreover, this discourse binds with the major features of classroom engagement, conceptualize and the impact of engaged learning on students' success. The editorial ends with a brief overview of the issue.
\end{abstract}

Keywords: Engaged learning, Pedagogical practices, Transformative praxis,

\section{Introduction}

Nepali mathematics education practices generally fall under public criticism because of being unable to attain the intended outcomes and poor academic achievement. The National Assessment of Students Achievement (NASA) indicates a decreasing trend of mathematics achievement since the last decade (Education Review Office [ERO], 2019). Besides the low achievement in mathematics, most students have no positive images, beliefs, and attitudes towards mathematics (Belbase, 2013; Lamichhane \& Belbase, 2017). The indication is that the mathematics education practices of Nepal have not adequately addressed cognitive and affective aspects of learners. Most of the classroom activities focus on solving the undue bookish questions to prepare the students for the so-called final examination for the explicit aims of achieving good marks or grades (Lamichhane, 2019). However, the students' national standardized test results do not indicate the success of the students in the specified content domains as claimed by the respective teachers and other concerned authorities. Is it an appropriate time for raising a 
question about the existing pedagogical practices of mathematics education? Why have mathematics teaching-learning activities in Nepal not considered cognitive, affective, and social aspects of learners? Who creates a barrier to incorporating these components in teaching-learning activities? Do the concerned authorities want to procrastinate the teaching-learning activities of mathematics within linear reductionist algorithms? If not, why teaching-learning activities in mathematics have not broken the conventional informing ways. These are some of the questions that mathematics educators have encountered during their academic and professional journeys. In our opinion, we must open a new discourse by incorporating cognitive, affective, and social aspects of learning to transform the existing informing pedagogy towards the transformative.

There are many reasons behind these deficiencies of mathematics education of Nepal that the practitioners have felt. Teachers' unawareness about contemporary philosophical, pedagogical; curricular discourses; their unwillingness to adopt an empowering pedagogical approach; and teachers' and students' beliefs, images and attitudes toward the nature of mathematics, pedagogy, curriculum and assessment become some of the significant hurdles to transform the mathematics education towards more inclusive and empowering ones (Luitel, 2009; Pant, 2017; Lamichhane, 2019; Shrestha, 2018; Dahal, 2020). Likewise, decontextualization of mathematics curriculum (Luitel, 2005), disengaged teaching-learning activities, and disciplinary egocentrism that prevail in mathematics education (Connor et al., 2015) help create a mathematical Othering (Abtathi et al., 2020) detaching the learners from the real-world problems. The detachment of learners from real-world problems further sprouts negativity in students' minds so that they feel bored, anxious, and disinterested in engaging in mathematics education. The disengaged teachinglearning activities in mathematics result in poor academic achievement (Yeh et al., 2019) and lead to avoidance of mathematics. In this regard, by acknowledging the significant roles of engaged learning to transform the mathematics pedagogy towards the more inclusive and empowering, we will try to briefly explore the attributes of engaged learning in the following subsections.

\section{Conceptualizing Engaged Learning}

In mathematics, student engagement is an integral approach and/or aspect of learning. This approach will enable students to be aware of what they need to know and experience the learning to promote understanding (Nyika \& Mwema, 2021). In general, when students are engaged in learning activities, they can participate with their cognitive, affective, and psychomotor dimensions and/or investment (Jansen, 2019). In particular, engagement is viewed as students' behaviours (observable), their own perceptions and beliefs, affective feeling, and sense of belongingness. Hence, 
engagement is defined as a complex construct that accounts for affective, cognitive and socio-behavioural aspects. In this line, Middleton et al. (2017, p. 667) viewed engagement as:

in-the-moment relationship between someone and her immediate environment, including the tasks, internal states, and others with whom $\mathrm{s} / \mathrm{he}$ interacts. Engagement manifests itself in activity, including both observable behaviour and mental activity involving attention, effort, cognition, and emotion.

So, engagement is an interactive association with students who do have with the content matter. Likewise, engaged learning for "active learning has been widely recognized as a more effective teaching methodology than traditional transmission models of teaching" (Kartina et al., 2011, p. 1). The discourse of student quality engagement in mathematics learning has been a central tension in relation to academic excellence and reputation in general and Nepal in particular.

Arriving at this stage, we define engagement as a collection of behaviours while learning by differentiating their learning compared to self and their peers. This is one of the common terminologies in the education sector. These processes shall exhibit cognitive interaction among the students and content. While demonstrating cognitive or other skills, student engagement in mathematics has a positive association with academic performance. Hence, engagement is considered students' input in learning activities concerning resources, commitment, and time (Krause \& Coates, 2008) by nurturing their cognitive, affective, and somatic dimensions. Students are provided with a learning environment to work with peers and share their experiences, feelings, knowledge, and skills without any fears and constraints to enrich and enhance their deep understanding of the phenomenon under consideration.

\section{Students' Engagement in Learning Mathematics}

Engagement in mathematical activities is essential to students' learning success. These successes promote continuing participation in mathematics (Christenso, 2012). However, scholars have debated that the process of engagement shall vary visibly in mathematics classrooms and school cultures. In general, the classroom cultures in mathematics are likely to reward the students who succeed at mathematics. This success neglected those students who see mathematics as complex or confusing or as a source of criticism and failure. In conceptualizing engaged mathematics learning, we are discussing the possibilities of active engagement in mathematics.

The underlying assumptions of engaged mathematics learning are explored, explained, and elaborated to connect the mathematical ideas (Shernoff, 2013). While connecting mathematical concepts in the context, the engaged students are 
likely to participate actively, valuing mathematical ideas genuinely and involved reflectively in deep understanding. Likewise, students need to know and experience how mathematics is being used in the context. The deep engagement in mathematics learning enables learners to raise fundamental questions related to mathematical reality, epistemology and values. For example, where does mathematics come from? How does mathematical knowledge construct and used to solve emerging and unconventional real-world problems? How do students work collaboratively and cooperatively for enhancing cultural and relational understanding? And how mathematics is connected with real world problems?

In response to the above questions, students need to reflect on mathematical enrichments and side-by-side enhancement critically. Becoming skeptical about a grand narrative for exploring better alternatives widens the notion of transformative praxis that can raise the consciousness of the mathematics teachers and even the students. These practices embrace the awareness and even critical stance toward the existing practices (Luitel \& Dahal, 2020). The existing practices shall inform the mathematics teachers to be reflexive in their practices. Likewise, the reflexive engagement of the mathematics teachers in teaching and/or learning shall contribute to conceptualize the transformative praxis as continuous professional development.

\section{Overview of the Issue}

In this issue, most of the articles have discussed the teaching-learning activities of mathematics, covering the different aspects of mathematics education. Kedar Nepal and his colleague explore the common and persistent sources of errors of undergraduate students in Algebra and Calculus courses in the context of the United States of America. Incorporating the grounded theory approach, they conclude that there are three external sources of common and persistent student errors: a) Difficulty with symbols and/or lack of attendance to the meaning of those symbols, b) Instructional practices, and c) Lack of knowledge. They have also provided an example of how the student made such types of errors in Calculus and Algebra.

Raj Kumar Tyata and team have highlighted the role of project-based learning to engage learners in meaningful mathematics learning. They argue that project-based learning created a learning environment in which learners could participate actively in the learning process. It also helped to relate the mathematical activities to the real-world problems that encourage students to become creative, critical, innovative, and imaginative independent learners that ultimately foster the transformative path of mathematics education.

In the article written by Ganesh Adhikari, the emerging and burning problems of ICT has been discussed. He has explored the teachers' perception of using ICTs 
in the mathematics classroom. The author did not find the gender difference in the level of perception; however, he unearthed some challenges of using ICTs in the mathematics classroom. These challenges were lack of knowledge, confidence, enough experience of teachers, lack of training to teachers, having less interest in using ICT and accessibility of ICT tools, lack of technical support, lack of genuine ICT Software, and unstable and unreliable internet connection at the schools.

To explore the undergraduate mathematics education practitioners' images of curriculum and their relation with pedagogical implications, Laxman Luitel and Binod Prasad Pant have used auto/ethnography research methodology. They have explored the two major metaphorical images of mathematics curriculum through critical reflective writing: curriculum as a prescription and curriculum as a cultural reproduction. Considering Habermasian Knowledge Constitutive Interest as a theoretical referent, they further highlighted the need for curricular and pedagogical transformation toward a more empowering and inclusive mode to better mathematics education practices.

Likewise, Krishan Kanta Parajuli has contributed in the field of Vedic Mathematics. The article provides a significant insight to the mathematics education practitioners in the South Asian subcontinent which has its own ways of solving elementary algebraic problems. He briefly describes the Vedic ways of solving elementary algebraic problems, which are quite different from the modern western techniques in teaching-learning activities. The article also helps break the deeprooted perceptions of Nepali mathematics education practitioners that there are no multiple ways of solving elementary algebraic problems. Similarly, it appeals to the learners not to depend upon only one way of doing or solving the elementary algebraic problems in school that deter students' creative and innovative ideas and ultimately imprison the learners within the mesh of so-called modern mathematical algorithm.

Finally, Mohammad Asfaque and Jeevan Kafle have discussed the method that can be used to find the values of the logarithmic function for any domains and bases to minimize the possible errors during basic mathematical operations. They explicitly exemplify their algorithm along with the graphical representation to justify their claims.

\section{References}

Abtathi, Y., Guillemette, D., Herheim, R., Lerman, S., Maheux, J-F., Valero, P. (2020). Otherness in Mathematics. A paper presented at a conference of Psychology of Mathematics Education. Sweden. 
Belbase, S. (2013). Image, anxieties, and attitudes toward mathematics. International Journal of Education in Mathematics, Science and Technology, 1(4), 230237.

Christenson, S. L., Reschly, A. L., \& Wylie, C. (Eds.). (2012). Handbook of research on student engagement. Springer Science \& Business Media.

Connor, A. M, Karmokar, S., \& Whittington, C. (2015). From STEM to STEAM: Strategies for enhancing engineering and technology Education. International Journal of Engineering and Pedagogy, 5 (1). https//doi.org/10.3991/ijep. v5i2.4458

Dahal, N. (2020). Teacher-students bonding in mathematics learning: An exploration of past, present, and future. AU eJournal of Interdisciplinary Research (ISSN: 2408-1906), 5(1).

Jansen A. (2019). Engagement with mathematics. In Lerman S. (Eds.), Encyclopedia of mathematics education. Springer, Cham. https://doi.org/10.1007/978-3319-77487-9_100040-1

Kartina, I., Samanhudi, U., Aisyah, S., Nulhakim, L., Evendi, S. S., \& Faturohman, M. (2011). Active Learning and Student Engagement in Mathematics at Madrasah Ibtidâ'iyah Al-Jauharotunnaqiyah. Excellence in Higher Education, 2(2), 109-113.

Krause, K. L., \& Coates, H. (2008). Students' engagement in first-year university. Assessment \& Evaluation in Higher Education, 33(5), 493-505.

Lamichhane, B. R. (2019). My images of mathematics, curriculum, pedagogy, and assessment: An Auto/ethnographic Inquiry [Unpublished M.Phil. Dissertation]. Kathmandu University, School of Education, Dhulikhel, Nepal.

Lamichhane, B. R., \& Belbase, S. (2017). Images of mathematics held by undergraduate students. International Journal of Emerging Mathematics, 1(2), 147-168. https://doi.org/10.12928/ijeme.v1i2.6647.

Luitel, B. C. (2009). Culture, worldview and transformative philosophy of mathematics education in Nepal: A cultural-philosophical inquiry [Unpublished doctoral dissertation]. Science and Mathematics Education Centre, Curtin University, Australia.

Luitel, B. C., \& Dahal, N. (2020). Conceptualizing transformative praxis. Journal of Transformative Praxis, 1(1), 1-8. https://doi.org/10.3126/jrtp.v1i1.31756 
Luitel, B.C. \& Taylor, P.C. (2005). Overcoming culturally dislocated curriculum in a transitional society: An autoethnographic journey towards pragmatic wisdom. Paper presented at the annual meeting of the American Educational Research Association (AERA), SIG: Self-Study of Teacher Education Practices, Montreal.

Nyika, J. M., \& Mwema, F. M. (2021). Conceptualizing student engagement and its role in meaningful learning and teaching experiences. In Fostering Meaningful Learning Experiences Through Student Engagement (pp. 159174). IGI Global.

Pant, B. P. (2017). Doing, teaching, learning, and thinking about mathematics - on becoming a transformative teacher. Journal of Education and Research, 7(1), 11-24. https://doi.org/10.3126/jer.v7i1.21237

Shernoff, D. J. (2013). Optimal learning environments to promote student engagement. Springer Science \& Business Media.

Shrestha, I. M. (2018). My pedagogical sensitization towards holistic mathematics education: A practitioner's inquiry, Unpublished MPhil Dissertation, Kathmandu University, Dhulikel Nepal.

Yeh, C. Y. C., Cheng, H. N. H., Chen, Z. H., Liao, C. C. Y., \& Chan, T. W. (2019). Enhancing achievement and interest in mathematics learning through MathIsland. Research and Practice in Technology Enhanced Learning, 14(1). https://doi.org/10.1186/s41039-019-0100-9. 